\title{
The accuracy of predictions about progress of patients on a stroke unit
}

\author{
N B Lincoln, J M Jackson, J A Edmans, M F Walker, V M Farrow, A Latham, \\ $\mathrm{K}$ Coombes
}

\begin{abstract}
The aim of the study was to check the accuracy of predictions about the factors which affect the progress, in physical abilities and activities of daily living, of patients admitted to a stroke unit. A series of 60 patients admitted consecutively to a stroke unit were assessed on tests of motor, functional and cognitive abilities at admission. On the basis of these assessments predictions were made about the abilities of the patients at discharge. Patients were assessed for level of motor abilities and activities of daily living at discharge and the accuracy of the predictions checked. Predictions were found to be significantly correlated with outcome but the relationships were not so close as to be useful for the clinical management of individual patients.
\end{abstract}

Studies on the prognosis of recovery from stroke have shown certain factors (such as perceptual abilities, age, incontinence, cognitive function) to be associated with a poor functional outcome. ${ }^{1-4}$

In $1989^{5}$ we reported a study of patients admitted to the Nottingham Stroke Unit. We found that patients' abilities on admission to the stroke unit were predictive of their abilities on discharge and to a lesser extent at nine months after the stroke. We developed predictive equations from the results of 70 patients but concluded that these needed to be validated on a further series of patients. The aim of this study was to check the accuracy of the predictive equations generated in the previous study and to investigate additional variables which might enhance the predictive value of these equations. If predictive equations do accurately indicate the level of abilities on discharge from hospital and the likely place of discharge they can assist the clinical management of patients. Once a patient reaches their expected level on discharge, plans can be made for future placement. This should be quicker than the present practice which is to wait until a patient seems to have stopped improving and then to make discharge plans. However, if predictions are to be used as a basis for the clinical management of patients they must be very accurate for each individual and not just reveal patterns which apply only to groups of patients.
Method

Patients were admitted to the Stroke Unit when they had recovered from the acute stage and were in need of rehabilitation but did not require acute medical care. Patients are referred to the unit from the general medical and the health care of the elderly wards throughout the Nottingham district. The patients are assessed by the consultant and senior registrar attached to the unit; those needing acute medical care, or who were unfit for intensive rehabilitation, or those patients with mild disability who were likely to return home within two weeks of the time of referral, were not accepted. Within the group of patients accepted there was therefore a bias towards relatively severely disabled patients who were nevertheless able to cope with intensive rehabilitation. Nearly all patients referred were accepted and those that were rejected because they were too dependent on nursing care or too medically ill were reviewed and were often taken to the unit at a later date.

During the first week after admission each patient was assessed on the following:

1 Rivermead Motor Function Assessment. ${ }^{6}$ This is subdivided into three scales: Gross Function, Leg and Trunk, and Arm.

2 Activities of Daily Living Scale-the Nottingham 10 point scale (NADL) including feeding, washing and dressing ${ }^{7}$ and a more detailed assessment, the Rivermead Activities of Daily Living Scale (RADL) which includes domestic activities. $^{8}$

3 Perceptual abilities-Rivermead Perceptual Assessment Battery, ${ }^{9}$ subtests-Right Left Copy Shapes (RLCS) and Cancellation.

4 Language abilities-Frenchay Aphasia Screening Test (FAST). ${ }^{10}$

5 Memory function-Logical Memory, subtest of Wechsler Memory Scale, ${ }^{11}$ immediate recall and half hour delay, and Recognition Memory Test Faces. ${ }^{12}$

6 Level of cognitive functioning-Coloured Progressive Matrices. ${ }^{13}$

7 Apraxia. $^{14}$

8 Mood-two questionnaires-the Wakefield Depression Inventory (WDI) ${ }^{15}$ and Hospital Anxiety and Depression Scale (HAD) ${ }^{16}$

9 Continence ratings-for continence of urine by day on a seven point scale devised for the study. This is scored as: catheterised or condom $=1$, incontinent $=2$, incontinent despite regular toileting $=3$, occasionally incontinent $=4$, continent if toileted regularly $=5$, continent except for accidents 
(for example, bottle spill $)=6$, continent $=7$. 10 Social support questionnaire.

In addition age, sex, marital status (scored as married $=0$ not married $=1$ ) and side of stroke were recorded. At discharge the following were recorded:

1 Gross function on the Rivermead Motor Function Assessment. ${ }^{6}$

2 ADL status on the NADL.?

3 Number of days on the unit.

4 Place of discharge (home, hospital, other accommodation or died).

\section{Patients' results}

Between October 1986 and February 1988 there were 63 patients admitted to the Stroke Unit. One patient was subsequently found not to have had a stroke and was excluded. One patient was admitted for two weeks respite care and also excluded and one patient was transferred back to the referring hospital before the initial assessment. The 60 patients were aged from 21 to 83 years, (mean 63.7 SD $10 \cdot 3$ years), and 35 were men. Most patients were married (38), the remainder being single (5), widowed (11), or divorced or separated (6). There were 30 patients with right hemisphere lesions, and 30 with left hemisphere lesions. At the end of the first week most patients (53) were continent of faeces and 47 were continent of urine apart from occasional accidents.

During admission there were two patients who died. These patients were both men with left hemisphere strokes and aged 60 and 83 years. Results at discharge were therefore based on the 58 patients who were discharged from the ward. The average time spent on the unit was 79 days (range 13 to 202 days) and $76 \%$ were discharged home.

Table 1 Comparison between predicted and actual abilities at discharge

\begin{tabular}{|c|c|c|c|c|c|c|c|c|c|c|c|c|c|c|c|}
\hline \multirow{2}{*}{$\begin{array}{l}\text { Gross Function } \\
\text { Predicted Score }\end{array}$} & \multicolumn{15}{|c|}{ Actual Score } \\
\hline & 0 & 1 & & 2 & 3 & 4 & 5 & 6 & 7 & 8 & 9 & 10 & 11 & & 12 \\
\hline 3 & 1 & & & & & & & & & & & & & & \\
\hline 4 & & 2 & & & & 2 & 1 & & & & & & & & \\
\hline 5 & & 5 & & 2 & & 2 & 3 & 1 & & & 2 & 1 & 1 & & \\
\hline 6 & & 1 & & 2 & 1 & 1 & & 3 & 2 & 1 & 3 & 2 & & & \\
\hline 7 & & & & & & & & & & 2 & 1 & 2 & & & \\
\hline 8 & & & & & & & & 1 & 2 & & & & & & \\
\hline 9 & & & & & & & & & & & & & & 1 & \\
\hline 10 & & & & & & & & & & & & & & 1 & \\
\hline 11 & & & & & & & & & & & & 1 & & & \\
\hline 12 & & & & & & & & & & & & 1 & & & \\
\hline 13 & & & & & & & & & & & & & 1 & 1 & \\
\hline \multicolumn{16}{|c|}{$\begin{array}{l}\text { Activities of Daily Living } \\
\qquad \text { Actual Score }\end{array}$} \\
\hline Predicted Score & & & & 2 & 3 & 4 & 5 & 6 & 7 & 8 & 9 & 10 & & & \\
\hline 3 & & & & 1 & & . & & & & & & & & & \\
\hline 4 & & & & & 5 & 1 & 2 & & & 1 & & & & & \\
\hline 5 & & & & 1 & 7 & 2 & 1 & & & 1 & 3 & 2 & & & \\
\hline 6 & & & & & 4 & 2 & 1 & & & 4 & 4 & 1 & & & \\
\hline 7 & & & & & & & & & 1 & 2 & 4 & & & & \\
\hline 8 & & & & & & & & 1 & & 1 & & & & & \\
\hline 9 & & & & & & & & & & 1 & & & & & \\
\hline 10 & & & & & & & & & & & 1 & 3 & & & \\
\hline \multicolumn{16}{|l|}{ Weeks on Unit } \\
\hline Predicted Score & $0-2$ & $3-4$ & $5-6$ & $7-8$ & $9-10$ & $11-12$ & $13-14$ & $15-16$ & $17-18$ & $19-20$ & $21-22$ & $23-24$ & $25-26$ & $27-28$ & $29-30$ \\
\hline $0-2$ & 1 & 4 & 2 & 1 & & & 1 & 1 & & & & & & & \\
\hline $3-4$ & 1 & & 1 & & 1 & & 1 & 1 & & & & & & & \\
\hline $5-6$ & & 1 & 3 & 1 & 1 & 2 & 3 & 1 & & & 1 & & & & \\
\hline $7-8$ & & & 4 & 2 & 1 & 2 & & & & & 2 & 1 & & & \\
\hline $9-10$ & & 1 & 1 & & 2 & & & 3 & 1 & 2 & 2 & 1 & & & 1 \\
\hline $11-12$ & & & & & & & & & 1 & 2 & & & & & \\
\hline
\end{tabular}


Comparison between predicted and actual abilities

The predictive equations derived from previous work on the unit ${ }^{5}$ were used to estimate abilities on discharge and place of discharge. These were:

Predicted Gross Function Score $=$ (Gross Function on Admission $\times 0.69)+($ Coloured Progressive Matrices $\times 0.08)+3.34$.

Predicted ADL Score $=($ Gross Function $\times$ $0.54)+$ (Coloured Progressive Matrices $\times$ $0 \cdot 09)+3 \cdot 27$.

Predicted Days on Unit $=$ (Gross Function on Admission $\times-8.6$ ) - (Marital Status $\times$ $23 \cdot 52)+115 \cdot 1$. Days on unit were converted into weeks.

Predicted Place of Discharge $=$ (Marital Status $\times 2.63)-($ Arm Score $\times 0.03)$ $($ RLCS $\times 0.02)+($ Cancellation $\times 0.03)-$ (Logical Memory $\times 0.03)+$ (Delayed Logical Memory $\times 0.02)+($ Age $\times 0.03)+$ $(\mathrm{ADL} \times 0 \cdot 17)-2 \cdot 21$.

If positive, predicted place $=$ home .

Predictions were compared with the actual discharge abilities. Results are shown in table 1. Results from cognitive assessments were missing for one patient, a 57 year old man who was discharged home 14 days after admission, because the assessor was on holiday. Predictions which included cognitive test results are therefore based on 57 patients. Results indicate that predictions were accurate for only eight patients on Gross Function score, seven patients on the ADL score and eight patients for time on unit. In addition, estimates within one point of actual score were only obtained for 12 patients on the Gross Function scale. There were discrepancies between expected gross function and actual gross function ranging between five points over estimate to six points underestimate. On the ADL scale there were 15 patients within one point of the expected but the discrepancies ranged from three points overestimate to five points underestimate. Time on the unit tended to be underestimated with only eight patients being discharged earlier than predicted. The greatest discrepancy being between a

Table 2 Correlations between admission and discharge variables

\begin{tabular}{|c|c|c|c|}
\hline \multirow[b]{2}{*}{ Admission } & \multicolumn{3}{|l|}{ Discharge } \\
\hline & $\begin{array}{l}\text { Gross } \\
\text { Function }\end{array}$ & $N A D L$ & $\begin{array}{l}\text { Days on } \\
\text { Unit }\end{array}$ \\
\hline Gross Function & $\underset{\star \star \star \star}{0.54}$ & $\underset{\star \star \star}{0.48}$ & $\begin{array}{l}-0.37 \\
\star \star\end{array}$ \\
\hline Leg and Trunk & $\begin{array}{l}0.58 \\
\star \star \star\end{array}$ & $\underset{\star \star \star}{0.45}$ & ${ }_{\star}^{-0.25}$ \\
\hline $\begin{array}{l}\text { Nottingham Activities } \\
\text { of Daily Living }\end{array}$ & $\begin{array}{l}0.37 \\
\star \star\end{array}$ & $\begin{array}{l}0.34 \\
\star \star\end{array}$ & $\begin{array}{l}-0 \cdot 10 \\
\text { NS }\end{array}$ \\
\hline Incontinence & $\underset{\star \star \star}{0.43}$ & $\underset{\star \star}{0.38}$ & $-0 \cdot 31$ \\
\hline $\begin{array}{l}\text { Recognition } \\
\text { Memory Faces }\end{array}$ & $\underset{\star}{0.26}$ & $\begin{array}{l}0.42 \\
\star \star\end{array}$ & $\star_{\star}^{-0.25}$ \\
\hline
\end{tabular}

NS, not significant

*Significance $p<0.05$

$\star \star$ Significance $p<0.01$

$\star \star \star$ Significance $p<0.001$. prediction of nine to 10 weeks and an actual inpatient stay of 29 weeks.

The place of discharge was correctly predicted for 47 patients, 44 of the $45(98 \%)$ who went home were correctly predicted but only three of the $12(25 \%)$ who did not go home were correctly predicted. The positive predictive value was $83 \%$ and negative predictive value $75 \%$.

The Spearman rank correlation coefficients between discharge scores and predicted scores were also calculated. These were for the gross function scale $r_{s}=0.56(p<0.001)$, NADL $r_{s}$ $=0.54(p<0.001)$ and days on unit $r_{s}=0.32$ $(\mathrm{p}<0.01)$. Correlations were also calculated between the discharge scores and the individual admission variables included in the predictive equations. These are shown in table 2. The correlations obtained were all significant apart from ADL score on admission and the number of days on the unit. The correlations between the individual variables which were included in each predictive equation and the outcome variable were all significant at the $1 \%$ level of significance and similar in magnitude to that between the predicted score and discharge variable.

\section{Additional factors affecting progress on the stroke} unit

To attempt to improve the accuracy of the predictive equations, stepwise multiple-regression analyses were carried out using all assessments including mood and apraxia, which were not recorded in the previous study. Days on the unit, motor function at discharge and ADL on discharge were the dependent variables. This was to assess the proportion of the variance that could be accounted for by the abilities assessed. The initial level of motor function accounted for the largest proportion of the variance on two of the three outcome measures and incontinence on one. Inclusion of mood and apraxia did not increase the accuracy of the predictive equation. The total variance accounted for varied between $39 \%$ for days on unit and $77 \%$ for ADL score. This is similar to the proportion of variance accounted for by the equations previously generated.

\section{Discussion}

Predictions about recovery can be generated and indicate which abilities are important in determining recovery. This information applies to groups of patients. For clinical purposes it is necessary to be able to predict an individual's progress. For this to be of any practical value it needs to be very accurate. Although the predictive equations generate values which correlate significantly with outcome they were not sufficiently accurate to be used as a basis for clinical decisions about individual patients.

The correlations between the predicted scores and actual scores at discharge were little different from the correlations between individual variables at admission and discharge. This indicates that using the multivariate model was little better at predicting 
outcome than using simpler univariate methods. The simplicity of the latter methods makes them more suitable for clinical use. These findings support the results of Barer and Mitchell ${ }^{17}$ with acute stroke patients who recommended a simple approach based on single variables instead of multivariate models.

Multiple regression analyses provide predictive equations for recovery. Our equations support our previous work indicating that incontinence and motor function are important determinants of outcome and generally those patients with more severe strokes do less well. This also supports work by Barer ${ }^{18}$ and Wade and Langton Hewer ${ }^{19}$ which indicate that incontinence is an important prognostic sign. The addition of mood and apraxia measures which had not been previously included did not improve the predictive accuracy of the equations. The proportion of variance accounted for by the equations was only moderate. For research purposes, however, they do suggest which factors have most influence on recovery and it may be that developments in therapy may be most appropriately directed at these. Alternatively all may be acting as non-specific markers of stroke severity and therefore would be unlikely to be influenced by rehabilitation though treatment in the acute stage could have impact.

The patients studied were a highly selected sample of stroke patients. They had been referred to a specialist stroke unit for intensive rehabilitation. The results obtained are therefore relevant to patients on similar units. The relative homogeneity of the group may have reduced the likelihood of being able to detect minor variations in outcome.

We therefore suggest that predictions about the progress of patients are useful indications of aspects which merit further investigation. They suggest direction for research into improving the outcome of stroke patients.
However, the accuracy of the predictions is not sufficient to provide a basis for clinical decisions about the management of individual patients.

We thank Dr R Kupfer and nursing staff of the Stroke Unit for We thank Dr R Kupfer and nursing staff of the Stroke Unit for their assistance with this study, Mr P Westwood, Miss H
Thomason, Miss R Gamlen and Miss A Emery for assistance Thomason, Miss R Gamlen and Miss A Emery for assistance
with data collection and Mrs A Dudley for typing the manuscript.

1 Andrews K, Brocklehurst JC, Richards B, Laycock PJ. The recovery of severely disabled stroke patients. Rheumatol recovery of severely disa

2 Wade DT, Skilbeck CE, Langton Hewer R. Predicting Barthel ADL score at 6 months after an acute stroke. Arch Phys Med Rehabil 1983;64:24-8.

3 Henley S, Petit S, Todd-Pokropek A, Tupper AM. Who goes home? Predictive factors in stroke recovery. $J$ Neurol Neurosurg Psychiatry 1985;48:1-6.

4 Feigenson JS, McDowell FH, Meese P, McCarthy ML, Greenberg SD. Factors influencing outcome and length of stay in a stroke rehabilitation unit. Stroke 1977;8:651-6.

5 Lincoln NB, Blackburn M, Ellis S, et al. An investigation of factors affecting progress of patients on a stroke unit. $J$ factors affecting progress of patients on a st
Neurol Neurosurg Psychiatry 1989;52:493-6.

6 Lincoln NB, Leadbitter D. Assessment of motor function in stroke patients. Physiotherapy 1979;65:48-51.

7 Ebrahim S, Nouri FM, Barer D. Measuring disability after stroke. J Epidemiol Comm Health 1985;39:86-9.

8 Whiting SE, Lincoln NB. An activities of daily living assessment for stroke patients. Br J Occup Therapy 1980;43:44-6.

9 Whiting SE, Lincoln NB, Cockburn J, Bhavnani G. The Rivermead Perceptual Assessment Battery. Windsor: NFER-Nelson, 1985.

10 Enderby P, Wood V, Wade D. Frenchay Aphasia Screening Test. Windsor: NFER-Nelson, 1987.

11 Wechsler D. A standardised memory scale for clinical use. $J$ Psychol 1945;19:87-95.

12 Warrington EK. Recognition Memory Test. Windsor: NFER-Nelson, 1984.

13 Raven JC. Guide to using the Coloured Progressive Matrices. London: Lewis, 1958.

14 Kertesz A, Ferro JM. Lesion size and location in ideomotor apraxia. Brain 1984;107:921-33.

15 Snaith RP, Ahmed SN, Mehta S, Hamilton M. Assessment of the severity of primary depressive illness. Psychol Med 1971;1:143-9.

16 Zigmund AS, Snaith RP. The Hospital Anxiety and Depression Scale. Acta Psychiatr Scand 1983;67:361-70.

17 Barer DH, Mitchell JRA. Predicting the outcome of acute stroke: Do multivariate models help? $Q J$ Med 1989;70: 27-39.

18 Barer DH. Continence after stroke: Useful predictor or goal of therapy? Age and Ageing 1989;18:183-91.

19 Wade DT, Hewer RL. Outlook after acute stroke: urinary incontinence and loss of consciousness compared in 532 patients. Q J Med 1985;56:601-8. 